\title{
William D. Stevenson (1913-2006): Atlantic Canada's Pioneer Neurosurgeon
}

The first Neurosurgery service in Atlantic Canada was established in Halifax, Nova Scotia in January of 1948 by Dr. William D. Stevenson. Under his leadership, a modern academic neurosurgical unit took shape at the Victoria General Hospital in Halifax and, for the first time, Atlantic Canadians had access to specialized neurosurgical care.

Dr. Stevenson was born in Hamilton, Ontario on December 24, 1913. He graduated from the University of Toronto Medical School in 1937. He completed four years of training in General Surgery with Dr. William Gallie at the University of Toronto, and then spent an additional year of general surgery training with Dr. Edward Archibald at McGill University in Montreal.

His training was interrupted by the Second World War and he served for two years in Basingstoke, England with the Canadian Military. Prior to his service overseas he spent six months of neurosurgical training with Canada's first neurosurgeon, Dr. Kenneth McKenzie, at the University of Toronto. Upon his return to Canada, Dr. Stevenson went back to Toronto for additional training in Neurosurgery under McKenzie and Dr. Harry Botterell. Stevenson finished his neurosurgical training in 1947 and was one of McKenzie's first neurosurgical residents.

Although he initially intended to establish a practice in Hamilton, Dr. Stevenson was successfully recruited to Halifax to start Atlantic Canada's first neurosurgical unit. Until that time, Canada's east coast lacked dedicated neurosurgical services. As the sole neurosurgeon in Atlantic Canada for the first seven years of his career, Dr. Stevenson's life was hectic with long hours spent in the operating room in Halifax and occasionally traveling to other Atlantic provinces to attend emergency cases.
Stevenson's accomplishment of developing the first academic neurosurgical program in Atlantic Canada laid the foundations for Neurosurgery in Halifax to grow to include ten neurosurgeons and clinical and research programs spanning all the subspecialties of Neurosurgery. Stevenson's leadership in Neurosurgery transcended Dalhousie University and the Victoria General Hospital; he served as President of the Canadian Neurosurgical Society in 1965 and was the first President of the Canadian Congress of Neurological Sciences.

After 26 years at the helm of the Neurosurgical Unit in Halifax, Dr. Stevenson retired to Ajax, Ontario in 1974. After his retirement he developed a passion for painting and became a serious amateur oil painter focusing mainly on landscapes. Each year one of his paintings is presented as the William D. Stevenson Research Award to a neurosurgery resident of the Dalhousie University program who has made a meritorious research contribution in Neurosurgery. On the occasion of the 50th anniversary of the establishment of neurosurgical services in Atlantic Canada in 1998, Stevenson provided guidance for the future generation of neurosurgeons that he thought would be relevant regardless of any technological advances. He advised that residents always be honest and open in their discussions with patients, their families, and colleagues. Dr. William D. Stevenson, Atlantic Canada's pioneer neurosurgeon, passed away on September 28, 2006 at the age of 93 .

Ivar Mendez and Karim Mukhida Halifax, Nova Scotia 